\title{
Adaptation to delayed auditory feedback
}

\author{
DOUGLAS I. KATZ and JAMES R. LACKNER \\ Brandeis University, Waltham, Massachusetts 02154
}

\begin{abstract}
Delayed auditory feedback disrupts the production of speech, causing an increase in speech duration as well as many articulatory errors. To determine whether prolonged exposure to delayed auditory feedback (DAF) leads to adaptive compensations in speech production. 10 subjects were exposed in separate experimental sessions to both incremental and constantdelay exposure conditions. Significant adaptation occurred for syntactically structured stimuli in the form of increased speaking rates. After DAF was removed, aftereffects were apparent for all stimulus types in terms of increased speech rates. A carry-over effect from the first to the second experimental session was evident as long as 29 days after the first session. The use of strategies to overcome DAF and the differences between adaptation to DAF and adaptation to visual rearrangement are discussed.
\end{abstract}

Adaptation to sensory rearrangement was first reported by Helmholtz (1866), who found that after continued exposure to visual displacement accurate sensory-motor coordination is gradually regained. Since his observations, many studies have been carried out to determine the nature and extent of these adjustments (Harris, 1965; Held, 1965; Held \& Freedman, 1963; Howard \& Templeton, 1966; Kohler, 1962; Rock, 1966; Snyder \& Pronko, 1952; Stratton, 1897; Wooster, 1923). Generaily, the initial errors in sensory-motor coordination caused by inversion or displacement of the visual scene diminish gradually over time; and, then, after removal of the distortion, a negative aftereffect can be measured.

In the early 1960 s, a new type of visual rearrangement study was introduced using temporal rather than spatial distortion. Smith (1962) had subjects carry out tasks such as writing, tracing, object manipulation, and panel control while watching their own performance on a television monitor which displayed a delayed signal from a video-tape recorder. The delayed visual feedback caused many changes in visuo-motor coordination, including increases in movement time, intensity of action, and frequency of errors. Other changes in movement organization occurred as well, such as extra repetitions during repetitive movements. Smith (1962) reported that there was little, if any, effective adapta-

Support was provided by the Spencer Foundation, the Rosenstiel Biomedical Sciences Foundation, and NASA Grant NGR 22-009-308. James R. Lackner is also at the Department of Psychology, Massachusetts Institute of Technology, Cambridge, Massachusetts 02139. Reprint requests should be addressed to James R. Lackner, Department of Psychology, Brandeis University, Waltham, Massachusetts 02154. We thank Ronald Calvanio for statistical advice. tion to delayed visual feedback and that what improvement did occur was limited and quite variable.

Shortly before Smith demonstrated the detrimental effects of visual delay on visuo-motor coordination, a number of investigators showed that speech production was disrupted by delayed auditory feedback (DAF); the earliest of these DAF studies were those of Lee in the early 1950s (Lee, 1950a, 1950b, 1951). DAF was produced by recording a subject's speech on a magnetic tape recorder with separate record and playback heads; then, by controlling the tape speed and the distance between the record and playback heads, the subject's voice could be delayed a predetermined amount when played back to him over headphones. By using a movable record or playback head, variable delays could be achieved.

The changes in speech that occur during exposure to DAF are in many ways similar to the alterations in visuomotor coordination elicited by delayed visual feedback. Analyses of speech produced under DAF have shown that there is a slowing down of the speech rate (Black, 1951; Chase, Harvey, Standfast, Rapin, \& Sutton, 1959; Fairbanks, 1955; Spilka, 1954; Rawnsley \& Harris, Note 1), an increase in speech intensity (Atkinson, 1953; Black, 1951; Fairbanks, 1955; Spilka, 1954), and a rise in fundamental frequency (Fairbanks, 1955). DAF also produces articulatory disturbances such as mispronunciations, omissions, substitutions, repetitions of syllables and continuant sounds and various nonrepetitive additions (Atkinson, 1953; Fairbanks \& Guttman, 1958; Hanley \& Tiffany, 1954; Lee, 1951; Tiffany \& Hanley, 1956).

The possibility of adaptation to DAF has been the subject of several investigations which have used widely different definitions of "adaptation." Although some investigators claim that adaptation occurs during exposure to DAF, as reflected by an 
increase in reading rate (Fillenbaum, 1965; Timmons, 1971; Winchester, Gibbons \& Krebs, 1959) and a decrease in such fluency breaks as repetitions and omissions (Tiffany \& Hanley, 1956), others failed to find any changes in speech rate (Atkinson, 1953; Tiffany \& Hanley, 1956) or in speech intensity (Atkinson, 1953). Aftereffects of DAF were reported by Black (1955), who found a decrease in speech rate after removal of DAF compared to the pre-DAF rate, but no change in speech intensity; in a related study, Tiffany and Hanley (1956) found that subjects most affected by DAF had a slower rate of speech subsequent to DAF exposure, and those least affected, a faster rate. However, Leith and Pronko (1957) found no difference between post-DAF and pre-DAF speech rates, and Zalosh and Salzman (1965) found no evidence for aftereffects of DAF in terms of speech rate, speech intensity, or frequency of articulatory errors.

Unlike the studies of visual rearrangement, which clearly demonstrate adaptation and subsequent negative aftereffects, the existing studies of adaptation to DAF are often contradictory and fail to provide conclusive evidence for adaptation and aftereffects. One problem apparent in all of these studies is the relatively short time the subjects are exposed to DAF; in no study is the exposure period more than a few minutes. In those studies in which adaptation is claimed, there may simply be an initial stabilization of performance during the first several minutes of exposure to DAF. Moreover, each study used only one type of reading material and defined adaptation by one measure alone-generally reading rate.

In the present study, adaptation to delayed auditory feedback was examined using exposure conditions of relatively prolonged durations. Both incremental and single-step introduction of DAF were used, because incremental exposure is known to enhance the rate of adaptation to other forms of sensory rearrangement (Ebenholtz, 1966, 1973; Graybiel, 1969; Graybiel \& Wood, 1969; Lackner \& Lobovits, 1977), as well as to allow adaptation to exposure conditions that normally preclude adaptation (Graybiel, 1969).

Earlier studies of adaptation to delayed auditory feedback have not included control stimuli or conditions to evaluate the possibility of practice effects. That is, performance might improve with additional exposure to the test stimuli and be confused with adaptation to the auditory delay. For this reason, several kinds of test materials were included in the present investigation to assess the relative importance of syntactic and memorial factors in adaptation to DAF. These stimuli included a long prose passage, memorized word lists, and memorized sentences; the advantage of the latter stimulus types is that accuracy of speech performance is already maximal and additional practice does not aid performance (cf. Lackner \& Levine, 1975; Shattuck \& Lackner, 1975). Changes in speech duration and relative frequencies of various types of articulation errors were used as indices of adaptation and aftereffects.

\section{METHOD}

Subjects

Ten Brandeis students, six females and four males, served voluntarily without pay. All were native speakers of English without known hearing or speech defects.

\section{Apparatus}

Delayed auditory feedback was produced with an Ampex AG-500 tape recorder, so modified that the distance between the custom record and playback heads could be adjusted by moving the sliding playback head. The subject spoke into an AKG D-1000E microphone from which the signal passed through the Ampex preamplifier to the record head, where it was recorded on the tape before passing a predetermined distance to the playback head, where it was recovered, amplified, and played back to the subject through a pair of Grason Stadler TDH-39Z headphones. By varying the distance between the record and playback heads and the speed of the tape $\left(7 \frac{1}{2}\right.$ or $\left.15 \mathrm{in} . / \mathrm{sec}\right)$, the playback of the subject's voice could be delayed in a continuous range from 43 to $766 \mathrm{msec}$; calibration was achieved by using a triggered dual beam oscilloscope (Tektronix 561A). The delay system could also be bypassed to allow the subject simultaneous auditory feedback of his voice. The subject's performance was recorded on a Magnecord 1024 tape recorder.

\section{Experimental Procedure}

Each subject was run twice, once in each of two experimental conditions. During an experimental session, the subject sat in a sound-insulated booth, wore headphones, and spoke into a microphone placed 10 in. from his or her mouth. Sound pressure level at the headphones was set individually for each subject at 25-30 dB above normal speaking level, as measured at the microphone. Each experimental session consisted of five parts or "feedback periods." The first two parts were under simultaneous and delayed auditory feedback, respectively (labeled SAF-pre and DAF-pre); the third involved prolonged exposure to DAF (labeled DAFexposure); and the last two parts were under delayed and simultaneous auditory feedback, respectively (labeled DAF-post and SAF-post).

SAF-pre. The first part of each session provided a baseline for each subject in relation to which his later performance could be compared. The subject was required to repeat four times each member of a set of five seven-word lists and five seven-word sentences that had been memorized ahead of time. The subject was asked to say the lists and sentences at a normal rate in a normal voice and to repeat each list and sentence in exactly the same manner every time. When satisfied with the repetitions of a particular list or sentence, the subject went on to the next list or sentence, in sequence. Following the lists and sentences, the subject was required to read a relatively difficult 284 -word prose passage that had not been memorized before the experiment.

DAF-pre. In the second part of the experiment, a 200-msec delay was introduced. A delay of this magnitude is maximally disruptive of speech production (Fairbanks \& Guttman, 1958). The subject was first required to read or to speak for $1 \mathrm{~min}$ in order to familiarize him with DAF. He was then requested to repeat the lists and sentences and to read the prose passage, as in the first part, trying again to speak in a normal voice and rate despite the DAF. Performance here is an indication of how disrupted the subject is by DAF. 
DAF-exposure. The third part of the experiment involved prolonged exposure to DAF. The subject read from Ernest Hemingway's Old Man and the Sea during 17 4-min intervals (68 $\mathrm{min}$ of DAF rotal) with 1 -min resı periods between intervals. The delay was either introduced gradually or in a single step, depending on which of the two experimental conditions was employed. In one condition, the delay was increased incrementally after each 4-min reading period, beginning with a 43-msec delay and then increasing first to $50 \mathrm{msec}$ and then, by 10 -msec steps, up to $200 \mathrm{msec}$. In the second condition, a $200-\mathrm{msec}$ delay was maintained throughout. Half of the subjects received the incremental-exposure condition first, and half received the constantdelay condition first.

DAF-post. In the fourth part of each experimental session, the subject once again repeated the lists and sentences and read the prose passage under 200-msec DAF, as in DAF-pre. Performance here compared with DAF-pre indicates the presence or absence of adaptation.

SAF-post. In the fifth and final part, in order to determine wherher there was an aftereffect of exposure to DAF, the subject again spoke the lists, sentences, and prose passage, but this time under SAF. The subject was not informed that this was the last part of the experiment.

After each experimental session, the subject was asked whether or not he had felt any self-improvement in the DAF-post condition compared to the DAF-pre condition. The subject was also asked to describe any strategies that he used to overcome the disruptive effects of DAF and whether he had experienced anything unusual in the SAF-post condition. At the conclusion of the second experimental session, the subject was asked which of the two experimental conditions seemed most difficult. The average time between experimental sessions for the subjects was 18 days, with a range of 10 to 29 days.

\section{RESULTS}

\section{Scoring}

The tape recordings from each experimental session were analyzed for articulatory errors, and these errors were assigned to one of four categories: repetitions, omissions, additions, or substitutions. Graphic records were made of each recording session using an inkwriting polygraph with the chart speed set at $30 \mathrm{~mm} / \mathrm{sec}$. Measurements were then taken from the graphs with an estimated accuracy of $\pm 0.5 \mathrm{~mm}$ to determine the duration of each of the lists, sentences, and a selected portion of the prose passage. Durations for the last three repetitions of each list or sentence were averaged, and these averages were pooled so that composite means for lists and for sentences could be obtained for each subject in each subcondition.

The data from each subject are presented separately in Appendices 1 and 2, and group data are summarized in Tables 1 and 4. The durations indicated are the composite means for the set of lists, set of sentences, and a selected portion of the prose passage; the articulatory errors are the total number for each stimulus set. The different categories of articulatory errors are considered individually below.

The data were treated by analyses of variance. Groups of three-, four-, and five-way analyses were carried out to examine the disruptive effects of DAF, the presence of adaptation to DAF, and the aftereffects of exposure to DAF. Within each group of analyses, separate analyses of variance were made of articulatory errors and durations for the three types of stimuli (lists, sentences, and prose passage). The analyses also evaluated possible interactions of amount of initial disruption, level of adaptation, and magnitude of aftereffect with experimental condition (incremental or constant delay), order of

Table 1

Mean Stimulus Duration (Seconds)

\begin{tabular}{llcccc}
\hline & & \multicolumn{4}{c}{ Feedback Period } \\
\cline { 4 - 6 } Stimulus & Exposure & SAF-pre & DAF-pre & DAF-post & SAF-post \\
\hline \multirow{2}{*}{ Lists } & Incremental & 4.2 & 7.1 & 5.9 & 3.4 \\
& Constant & 4.4 & 6.8 & 6.1 & 3.6 \\
Sentences & Incremental & 1.9 & 3.3 & 2.9 & 1.8 \\
& Constant & 1.9 & 3.2 & 3.0 & 1.8 \\
Prose & Incremental & 57.9 & 84.1 & 73.8 & 51.7 \\
& Constant & 58.0 & 81.4 & 77.8 & 52.4 \\
\hline
\end{tabular}

Table 2

Mean Number of Articulatory Errors

\begin{tabular}{|c|c|c|c|c|c|}
\hline \multirow[b]{2}{*}{ Stimulus } & \multirow[b]{2}{*}{ Exposure } & \multicolumn{4}{|c|}{ Feedback Period } \\
\hline & & SAF-pre & DAF-pre & DAF-post & SAF-post \\
\hline Lists & $\begin{array}{l}\text { Incremental } \\
\text { Constant }\end{array}$ & $\begin{array}{l}.6 \\
.3\end{array}$ & $\begin{array}{l}9.5 \\
5.1\end{array}$ & $\begin{array}{l}3.6 \\
4.3\end{array}$ & $\begin{array}{l}.2 \\
.4\end{array}$ \\
\hline Sentences & $\begin{array}{l}\text { Incremental } \\
\text { Constant }\end{array}$ & $\begin{array}{l}.1 \\
.3\end{array}$ & $\begin{array}{l}6.7 \\
4.4\end{array}$ & $\begin{array}{l}3.0 \\
3.0\end{array}$ & $\begin{array}{l}.2 \\
.6\end{array}$ \\
\hline Prose & $\begin{array}{l}\text { Incremental } \\
\text { Constant }\end{array}$ & $\begin{array}{l}1.5 \\
1.5\end{array}$ & $\begin{array}{l}20.2 \\
18.0\end{array}$ & $\begin{array}{l}14.6 \\
12.0\end{array}$ & $\begin{array}{l}2.0 \\
1.0\end{array}$ \\
\hline
\end{tabular}


Table 3

Mean Stimulus Duration (Seconds)

\begin{tabular}{llcccc}
\hline & & \multicolumn{4}{c}{ Feedback Period } \\
\cline { 3 - 6 } Stimulus & Exposure & SAF-pre & DAF-pre & DAF-post & SAF-post \\
\hline \multirow{2}{*}{ Lists } & Session 1 & 4.5 & 8.0 & 6.5 & 3.6 \\
& Session 2 & 4.1 & 6.0 & 5.5 & 3.4 \\
Sentences & Session 1 & 1.9 & 3.7 & 3.1 & 1.8 \\
& Session 2 & 1.8 & 2.7 & 2.8 & 1.8 \\
\multirow{2}{*}{ Prose } & Session 1 & 59.6 & 96.0 & 81.0 & 54.0 \\
& Session 2 & 56.3 & 69.5 & 70.7 & 50.1 \\
\hline
\end{tabular}

Table 4

Mean Number of Articulatory Errors

\begin{tabular}{llcccc}
\hline & & \multicolumn{4}{c}{ Feedback Period } \\
\cline { 3 - 6 } Stimulus & Exposure & SAF-pre & DAF-pre & DAF-post & SAF-post \\
\hline \multirow{2}{*}{ Lists } & Session 1 & .7 & 10.2 & 4.7 & .5 \\
& Session 2 & .2 & 4.0 & 3.2 & .1 \\
Sentences & Session 1 & .1 & 6.8 & 3.2 & .4 \\
& Session 2 & .3 & 4.3 & 2.8 & .4 \\
Prose & Session 1 & 2.1 & 21.8 & 14.8 & 1.6 \\
& Session 2 & 1.0 & 16.4 & 11.8 & 1.4 \\
\hline
\end{tabular}

presentation of condition, order of experimental session, and type of linguistic stimulus (word list or sentence).

\section{Initial Disruption}

A significant increase in the number of articulatory errors and in stimulus durations occurred in the DAF-pre period compered to the SAF-pre period for all linguistic stimuli (lists, sentences, and prose passage) indicating that DAF disrupted production of all categories (see Table 5). There was a significant interaction $(p<.001)$ between the two feedback conditions (SAF and DAF) and type of stimulus (lists and sentences) in duration, with sentences being less disrupted than lists in terms of speaking rate.

\section{Adaptation}

Comparing the DAF-post to the DAF-pre period, the number of articulatory errors decreased significantly $(p<.05)$ in the sentences and prose passages and decreased in lists, though not significantly. Although the durations of all linguistic categories decreased in DAF-post relative to DAF-pre, only lists decreased significantly in speaking duration $p<.01)$. This differential effect on lists and sentences produced a significant interaction between feedback period and stimulus type $(p<.01)$. The results of these analyses are summarized in Table 6.

\section{Aftereffects}

A comparison of the SAF-pre period with the SAF-post period showed significantly shorter durations in SAF-post for all stimulus types (see Table 7). This effect was significantly less for sentences than for lists $(p<.001)$. No differences were found in terms of articulatory errors.

\section{Experimental Condition}

No significant effect of incremental vs. constant delay on adaptation in terms of articulatory errors or of duration changes appeared. There was, however, an interaction in all of these categories between experimental condition and the order in which the condition was presented, indicating a possible carry-

Table 5

Analyses of Variance of Disruption in Articulatory Error and Duration Measures for All Stimulus Types (SAF-pre vs. DAF-pre)

\begin{tabular}{|c|c|c|c|c|c|}
\hline Measure & Stimulus & Mean Square & Mean Square Error & df & $\mathbf{F}$ \\
\hline Errors & $\begin{array}{l}\text { Lists } \\
\text { Sentences } \\
\text { Prose }\end{array}$ & $\begin{array}{r}448.900 \\
286.225 \\
3,097.600\end{array}$ & $\begin{array}{r}59.511 \\
14.225 \\
118.541\end{array}$ & $\begin{array}{l}1,9 \\
1,9 \\
1,9\end{array}$ & $\begin{array}{c}7.54^{*} \\
20.12^{* *} \\
26.13 \dagger\end{array}$ \\
\hline Duration & $\begin{array}{l}\text { Lists } \\
\text { Sentences } \\
\text { Prose }\end{array}$ & $\begin{array}{l}64,858.600 \\
16,289.290 \\
55,338.720\end{array}$ & $\begin{array}{r}2,879.857 \\
1,005.197 \\
229,912.500\end{array}$ & $\begin{array}{l}1,9 \\
1,9 \\
1,9\end{array}$ & $\begin{array}{l}22.52^{* *} \\
16.21^{* *} \\
24.07 \dagger\end{array}$ \\
\hline
\end{tabular}


Table 6

Analyses of Variance of Adaptation in Articulatory Error and Duration Measures for All Stimulus Types (DAF-pre vs. DAF-post)

\begin{tabular}{llrrrrr}
\hline Measure & Stimulus & Mean Square & Mean Square Error & df & F \\
\hline & Lists & 102.400 & 26.011 & 1,9 & 3.94 \\
Errors & Sentences & 65.025 & 10.914 & 1,9 & $5.96^{*}$ & $7.20^{*}$ \\
& Prose & 336.400 & 46.732 & 1,9 & 1,9 & $12.87^{* *}$ \\
& Lists & $8,675.883$ & 752.560 & 408.489 & 1,9 & 1.84 \\
& Suration & Prose & $430,977.600$ & $108,721.100$ & 1,9 & 3.96 \\
\hline
\end{tabular}

*Significant at $p<.05$

**Significant at $p<.01$

Table 7

Analyses of Variance of Aftereffect in Articulatory Error and Duration Measures for all Stimulus Types (SAF-pre vs. SAF-post)

\begin{tabular}{clrrrr}
\hline Measure & Stimulus & Mean Square & Mean Square Error & df & F \\
\hline \multirow{2}{*}{ Errors } & Lists & .225 & .225 & 1,9 & 1.00 \\
& Sentences & .400 & .178 & 1,9 & 2.25 \\
& Prose & .000 & 1.278 & 1,9 & .00 \\
Duration & Lists & $5,347.652$ & 203.084 & 1,9 & $26.33^{* *}$ \\
& Sentences & 172.226 & 12.296 & 1,9 & $14.00^{*}$ \\
& Prose & $312,936.100$ & $11,067.990$ & 1,9 & $28.27^{* *}$ \\
\hline
\end{tabular}

* Significant at $p<.01$

**Significant at $p<.001$

over effect from the first experimental session to the second. To confirm the presence of carry-over, analyses were carried out comparing each subject's first and second experimental sessions over the various parameters of the experiment. A significant decrease in the amount of disruption from the first to second session was evident and appeared as an interaction between feedback periods (SAF-pre vs. DAF-pre) and experimental session for duration $(p<.05$ for lists and for sentences; $p<.001$ for prose), and for articulatory errors on the prose passage $(p<.05)$; articulatory errors on lists and sentences decreased as well, but not significantly.

A decrease also occurred in the DAF-pre measures of the second session compared to the DAF-pre measures of the first session in all stimulus and measurement categories. The mean durations of all stimulus materials and the total number of articulatory errors on lists were actually lower in the DAF: pre condition of Session 2 than in the DAF-post condition of Session 1 (see Tables 3 and 4). An analysis of variance indicated a significant decrease $(p<.05)$ between the first and second sessions in stimulus mean duration averaged across DAF-pre and DAF-post periods in each session; the total errors also decreased between sessions in each stimulus category, but this difference was not statistically significant. The results are illustrated by experimental session in Tables 3 and 4 .

\section{Articulatory Errors}

The mean number of articulatory errors across subjects in each category (substitutions, repetitions, omissions, and additions) for each of the feedback conditions is illustrated for Session 1 in Figure 1.
As can be seen; all types of errors increased from the SAF-pre to DAF-pre periods, decreased from the DAF-pre to DAF-post period, and decreased in the SAF-post period to the SAF-pre level. Repetitions were the most common error followed by omissions, additions, and substitutions. The percent decrease from the DAF-pre to DAF-post periods followed the same order of magnitude: repetitions, $42.1 \%$; omissions, $32.1 \%$; additions, $25.0 \%$; substitutions,

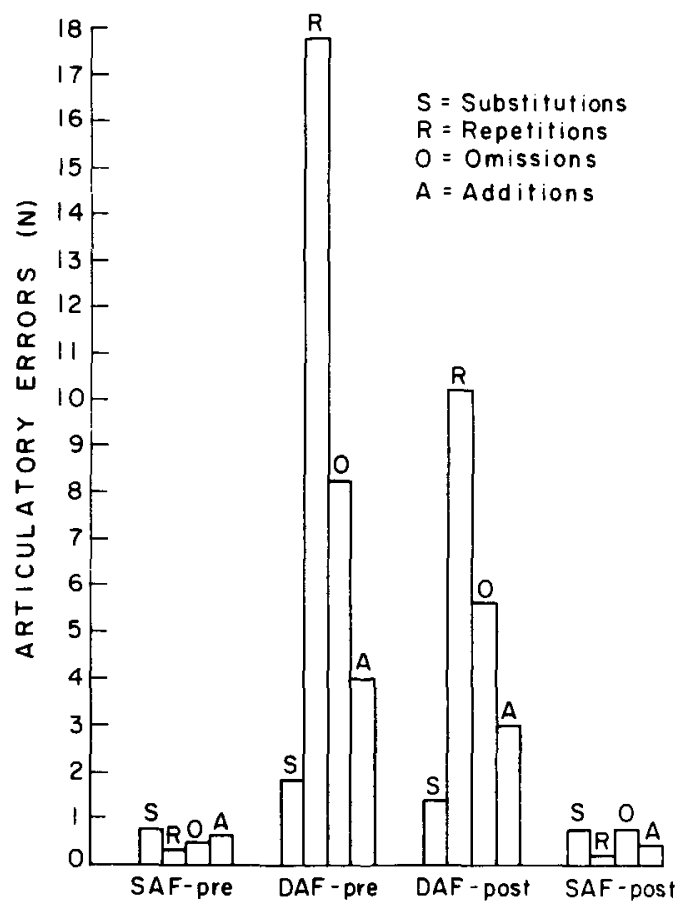

Figure 1. Mean number of different forms of arliculators errors in each feedback period of Session 1. 
$22.2 \%$. The errors in Session 2 followed the same pattern.

\section{Subjective Reports}

In response to whether they noticed anything unusual in the SAF-post condition, three subjects reported a feeling of relief after DAF was removed and three subjects thought they had been speaking faster in the SAF-post period during one of their sessions; others reported such changes as slurring, clearer speech, and greater concentration on speech production. All but one subject found the incremental delay condition easier than constant delay, although these subjects did not think that their performance was necessarily superior in that condition. Nine of the 10 subjects believed they had performed better in DAF-post than in DAF-pre in at least one experimental session, 4 thought they had done better on both sessions. Thus, in general, the subjects had correctly assessed their performance.

The subjects reported having tried various strategies to overcome the disruptive effects of DAF. One common strategy was to block selectively auditory feedback by trying to disregard the DAF coming through the headphones and relying on boneconducted auditory feedback; most subjects found this difficult because of the high intensity of the DAF. Other less common strategies included (a) speaking in a discontinuous, staccato fashion; (b) speaking without pauses; (c) slowing the speaking rate; (d) increasing the speaking rate; (e) concentrating on the typescript when reading the prose passage; ( $f$ ) concentrating on speech production, including position of the lips and tongue, and attempting to watch lip movements; (g) not concentrating on speaking; (h) maintaining a rhythm; (i) speaking at a constant rate; (j) speaking louder; and (k) enunciating more carefully. The subjects reported trying similar strategies in each of the two experimental sessions, but retaining only those strategies with which they had had the most success.

\section{DISCUSSION}

The experimental results indicate that some adaptation to delayed auditory feedback is possible and that the extent and nature of this adaptation is dependent on the amount of initial disruption and the type of stimulus used. Adaptation to delayed auditory feedback takes place only when there is a substantial amount of initial disruption, and, accordingly, a significant need for compensation. The lesser disruption and consequent lack of significant adaptation for sentences compared to word lists in terms of duration is likely related to evidence that the size and complexity of the control patterns used to organize movements of the vocal apparatus are greater for syntactic than for nonsyntactic material (Lackner \& Levine, 1975). Auditory feedback i, therefore, less important, in that, with syntactic material, speakers have more information about what they are going to say over a greater time period. In addition to a greater reliance on auditory feedback, the disruption of the nonsyntactically structured list stimuli during delayed auditory feedback is perhaps related to the shorter durations of the innervation patterns of the list stimuli which are closer to the critical delay time of $200 \mathrm{msec}$ than are those of the sentence stimuli.

This relationship between disruption and adaptation controverts the possibility of a significant practice effect. If a large practice effect were present, then decreases in errors and durations of the stimuli should be independent of the amount of initial disruption; they were not. Moreover, since the subjects were trying to say the memorized word lists and sentences at precisely the same rate during all four test periods, the rate that had been set in the SAF-pre test period, a practice effect should take the form of an increase in accuracy of repetition, with the mean durations of repetitions remaining equal to those of the SAF-pre values for the different stimuli. However, the overall accuracy of repetition of individual word lists and sentences did not improve in successive feedback periods, whereas their mean durations varied in a manner indicative of adaptive compensations in speech production. Similarly, an analysis of articulatory-error frequencies for all three types of stimuli fails to yield a pattern consistent with a practice effect; there are no significant differences in error frequencies between SAF-pre and SAF-post such as would be expected with a significant practice effect.

An aftereffect is evident for all stimulus materials and appears as an increased speech rate after DAF is removed. This finding is contrary to that of Black (1955), who reported a slowing of speech after exposure to delayed auditory feedback. The aftereffect may not be entirely dependent on adaptation, because small aftereffects were apparent even for stimuli in which minimal adaptation was evident. Despite this qualification, there is a clear relationship between aftereffect magnitude, amount of adaptation, and magnitude of initial disruption, e.g., the durations of the word lists were more disrupted and showed more adaptation than those of the sentences, and word lists likewise exhibited significantly greater aftereffects.

Caution is necessary in interpreting the shortened post-SAF durations as an aftereffect, since it might be claimed that subjects naturally speed up in anticipation of the end of the experimental session. Such an interpretation is unlikely, at least for the first experimental session, because the subjects had not been 
told when they had reached the last part of the experiment. The aftereffect most likely resulted from an overcompensation in speaking rate that occurred when the constraining effects of delayed auditory feedback were removed. This release is apparent in the feeling of "relief" noted by some subjects in the last SAF condition.

Several factors may account for nonsignificant results in certain measures of adaptation and aftereffects, the most important of which is high intersubject variability. Variability was especially evident in the prose passage, probably due to its greater length and complexity. The impact of delayed auditory feedback on the 10 subjects ranged from almost no apparent disruption in some subjects to nearly complete incapacitation in others; the amount of adaptation elicited is correspondingly variable. It is notable, nonetheless, that even those subjects who appear to be minimally disrupted by DAF report that speaking is difficult and requires considerably more effort than under normal conditions.

A striking feature of this study is the transfer effect from the first to the second experimental session, evident even in the subject with the longest interval between sessions ( 29 days). Transfer is most apparent in the measures of speech duration which were much less disrupted in the second delayed auditory feedback session. This carry-over is quite different from that which occurs with adaptation to visual displacement where carry-over of adaptation is small after $48 \mathrm{~h}$ (Lackner \& Lobovits, 1977), although it may persist at measurable levels over 2 weeks (Yachzel \& Lackner, 1977). It appears that in the second session, subjects retained and utilized strategies they had developed during the first session. Accordingly, any potential differences between the incremental and constant delay exposure conditions cannot be determined, because they are masked by the carry-over effect which produces a reduction in the amount of improvement in the second session regardless of experimental conditions. Most subjects reported that the incremental exposure condition was less difficult, but this may be the result of the shortened period of exposure to maximal delay during the incremental delay condition.

It is evident that adaptation to delayed auditory feedback has different characteristics than the compensation that occurs during exposure to visual rearrangement. As already noted, exposure to delayed auditory feedback elicits long-lasting carryover effects to subsequent exposures and is materialdependent as well as strategy-dependent. The process of adaptation to auditory delay is an active one in which the subject tries to develop strategies to compensate for the disruptive effects of the delay. By contrast, adaptation to visual displacement can occur without visual feedback informing the subject about the accuracy of his visuomotor coordination, e.g., without information about errors between the position of the hand and external targets (Held, 1965). Moreover, using incremental changes in visual displacement, adaptation can be evoked without the subject even realizing that a rearrangement is present (Howard, 1968). In the absence of error recognition, the possibility of developing a response strategy, such as that necessary for adaptation to delayed auditory feedback, is eliminated. It is clear that, despite improvements in speech production, the subject is aware at all times that a delay is present and can compensate for its disruptive effect only by a conscious strategic effort. Hanley, Tiffany, and Brungard (1958) note that subjects attempt to overcome disruption by a "strength of effort" that is also reflected in terms of physiological measures such as galvanic skin response.

The strategies that the subjects used to counteract delayed auditory feedback fall into two general categories: (a) altering the feedback relied upon, and (b) changing the articulatory motor pattern. Speech feedback is normally derived from three sources: kinesthetic and proprioceptive feedback from the vocal apparatus and musculature, auditory feedback through bone structures, and auditory feedback transmitted through the air. Delayed auditory feedback causes a direct disruption of only air-conducted auditory feedback, and a common strategy is to try to ignore this input while carefully enunciating and attending to proprioceptive and kinesthetic feedback from the tongue and lips. Another strategy of this type involves speaking at high intensity and focusing on the bone-conducted auditory feedback. The second type of strategy uses changes in motor sequencing, such as varying the rhythm and rate of speech, speaking in a discontinuous rhythm or in a regular rhythm out of synchrony with the delay duration, speaking faster or slower, or pausing until the delayed feedback "catches up." Each of these distinct strategies defeats the delay by preventing a synchronization of mean syllabic duration with delay time, thereby minimizing disruption.

The question still remains as to whether it would be possible to adapt totally to delayed auditory feedback so that speech production would return to normal. That is, would longer exposure durations elicit continually greater improvement, or is there a limit beyond which further improvement is no longer possible? The results reported here tend to support the latter conclusion since the magnitude of improvement leveled off during the second experimental session. Once strategies are acquired, it seems that little improvement beyond refining these strategies is attained and that these strategies by themselves are only partially effective.

In trying to understand why it is possible to achieve complete adaptation, sans strategies, to visual displacement but not to delayed auditory feedback, it is important to realize that adaptation to visual displacement can be achieved by a simple postural 
remapping, e.g., a change in the registered orientation of head on trunk, of a magnitude and direction to compensate exactly for the visual displacement (cf. Harris, 1965; Lackner, 1973a, b; 1976a, b). Such remappings do not produce "side effects" that disrupt other aspects of sensorimotor coordination. By contrast, there is no sensory or postural change that could by itself eliminate the disruptive consequences of delayed auditory feedback without disturbing other aspects of auditory localization and analysis. Speeding up the rate of processing of air- borne auditory feedback is not a possible solution, because the time that has to be made up is several hundred milliseconds; furthermore, one implication of such a speedup leads to physical impossibilities, e.g., the resolution of an external sound would often have to begin before the sound arose in the environment. Although adaptation to delayed auditory feedback involves the development of compensatory strategies or maneuvers, and is thus qualitatively different from adaptation to visual rearrangement, it is no less remarkable or complex.

Appendix 1

Mean Durations (Seconds) of Lists, Sentences, and Prose Passage in Each Feedback Period During Incremental and Constant Delay Exposure Conditions

\begin{tabular}{|c|c|c|c|c|c|c|}
\hline & \multirow[b]{2}{*}{ Exposure } & \multirow[b]{2}{*}{ Stimulus } & \multicolumn{4}{|c|}{ Feedback Period } \\
\hline & & & SAF-pre & DAF-pre & DAF-post & SAF-post \\
\hline \multirow{2}{*}{ Subject 1} & Incremental & $\begin{array}{l}\text { Lists } \\
\text { Sentences } \\
\text { Prose }\end{array}$ & $\begin{array}{r}3.62 \\
1.83 \\
48.00\end{array}$ & $\begin{array}{r}7.82 \\
3.75 \\
84.67\end{array}$ & $\begin{array}{r}6.35 \\
3.18 \\
84.70\end{array}$ & $\begin{array}{r}3.05 \\
1.74 \\
46.07\end{array}$ \\
\hline & Constant & $\begin{array}{l}\text { Lists } \\
\text { Sentences } \\
\text { Prose }\end{array}$ & $\begin{array}{r}3.67 \\
1.85 \\
47.83\end{array}$ & $\begin{array}{r}6.87 \\
3.14 \\
77.07\end{array}$ & $\begin{array}{r}6.21 \\
3.08 \\
89.03\end{array}$ & $\begin{array}{r}3.29 \\
1.95 \\
48.83\end{array}$ \\
\hline \multirow{2}{*}{ Subject 2} & Incremental & $\begin{array}{l}\text { Lists } \\
\text { Sentences } \\
\text { Prose }\end{array}$ & $\begin{array}{r}4.27 \\
1.85 \\
56.37\end{array}$ & $\begin{array}{r}5.98 \\
2.34 \\
64.67\end{array}$ & $\begin{array}{r}5.95 \\
2.11 \\
67.17\end{array}$ & $\begin{array}{r}4.32 \\
1.84 \\
58.23\end{array}$ \\
\hline & Constant & $\begin{array}{l}\text { Lists } \\
\text { Sentences } \\
\text { Prose }\end{array}$ & $\begin{array}{r}4.39 \\
1.85 \\
58.40\end{array}$ & $\begin{array}{r}5.02 \\
1.82 \\
56.93\end{array}$ & $\begin{array}{r}5.39 \\
2.33 \\
62.27\end{array}$ & $\begin{array}{r}4.24 \\
1.78 \\
49.17\end{array}$ \\
\hline \multirow{2}{*}{ Subject 3} & Incremental & $\begin{array}{l}\text { Lists } \\
\text { Sentences } \\
\text { Prose }\end{array}$ & $\begin{array}{r}3.30 \\
1.55 \\
53.90\end{array}$ & $\begin{array}{r}7.07 \\
2.61 \\
91.87\end{array}$ & $\begin{array}{r}6.82 \\
3.83 \\
76.93\end{array}$ & $\begin{array}{r}2.53 \\
1.59 \\
42.33\end{array}$ \\
\hline & Constant & $\begin{array}{l}\text { Lists } \\
\text { Sentences } \\
\text { Prose }\end{array}$ & $\begin{array}{r}3.07 \\
1.65 \\
56.73\end{array}$ & $\begin{array}{r}6.25 \\
2.19 \\
61.57\end{array}$ & $\begin{array}{r}4.90 \\
2.22 \\
51.20\end{array}$ & $\begin{array}{r}2.30 \\
1.48 \\
45.97\end{array}$ \\
\hline \multirow{2}{*}{ Subject 4} & Incremental & $\begin{array}{l}\text { Lists } \\
\text { Sentences } \\
\text { Prose }\end{array}$ & $\begin{array}{r}3.63 \\
1.87 \\
58.53\end{array}$ & $\begin{array}{r}6.07 \\
2.88 \\
91.07\end{array}$ & $\begin{array}{r}5.56 \\
3.35 \\
83.53\end{array}$ & $\begin{array}{r}3.24 \\
1.64 \\
51.80\end{array}$ \\
\hline & Constant & $\begin{array}{l}\text { Lists } \\
\text { Sentences } \\
\text { Prose }\end{array}$ & $\begin{array}{r}3.00 \\
1.65 \\
56.73\end{array}$ & $\begin{array}{r}4.54 \\
2.19 \\
61.57\end{array}$ & $\begin{array}{r}3.68 \\
2.22 \\
51.20\end{array}$ & $\begin{array}{r}2.66 \\
1.48 \\
45.97\end{array}$ \\
\hline \multirow{2}{*}{ Subject 5} & Incremental & $\begin{array}{l}\text { Lists } \\
\text { Sentences } \\
\text { Prose }\end{array}$ & $\begin{array}{r}4.41 \\
2.18 \\
69.50\end{array}$ & $\begin{array}{r}14.69 \\
7.60 \\
145.23\end{array}$ & $\begin{array}{r}8.17 \\
3.43 \\
80.63\end{array}$ & $\begin{array}{r}3.24 \\
1.77 \\
54.73\end{array}$ \\
\hline & Constant & $\begin{array}{l}\text { Lists } \\
\text { Sentences } \\
\text { Prose }\end{array}$ & $\begin{array}{r}4.50 \\
1.96 \\
52.67\end{array}$ & $\begin{array}{r}7.54 \\
3.69 \\
83.27\end{array}$ & $\begin{array}{r}8.21 \\
4.34 \\
93.80\end{array}$ & $\begin{array}{r}3.25 \\
1.72 \\
48.20\end{array}$ \\
\hline \multirow{2}{*}{ Subject 6} & Incremental & $\begin{array}{l}\text { Lists } \\
\text { Sentences } \\
\text { Prose }\end{array}$ & $\begin{array}{r}3.46 \\
1.91 \\
51.97\end{array}$ & $\begin{array}{r}6.01 \\
3.53 \\
76.70\end{array}$ & $\begin{array}{r}4.81 \\
3.10 \\
69.37\end{array}$ & $\begin{array}{r}3.07 \\
1.80 \\
53.40\end{array}$ \\
\hline & Constant & $\begin{array}{l}\text { Lists } \\
\text { Sentences } \\
\text { Prose }\end{array}$ & $\begin{array}{r}3.57 \\
1.96 \\
60.50\end{array}$ & $\begin{array}{r}8.09 \\
5.32 \\
112.70\end{array}$ & $\begin{array}{r}6.83 \\
4.39 \\
113.17\end{array}$ & $\begin{array}{r}3.32 \\
1.87 \\
56.50\end{array}$ \\
\hline \multirow{3}{*}{ Subject 7} & Incremental & $\begin{array}{l}\text { Lists } \\
\text { Sentences } \\
\text { Prose }\end{array}$ & $\begin{array}{r}3.27 \\
1.60 \\
55.73\end{array}$ & $\begin{array}{r}4.86 \\
2.18 \\
53.97\end{array}$ & $\begin{array}{r}3.87 \\
1.90 \\
53.13\end{array}$ & $\begin{array}{r}2.41 \\
1.62 \\
45.10\end{array}$ \\
\hline & Constant & $\begin{array}{l}\text { Lists } \\
\text { Sentences } \\
\text { Prose }\end{array}$ & $\begin{array}{r}3.57 \\
1.49 \\
51.47\end{array}$ & $\begin{array}{r}5.69 \\
2.84 \\
83.57\end{array}$ & $\begin{array}{r}5.02 \\
2.56 \\
58.53\end{array}$ & $\begin{array}{r}3.05 \\
1.51 \\
47.87\end{array}$ \\
\hline & Incremental & $\begin{array}{l}\text { Lists } \\
\text { Sentences }\end{array}$ & $\begin{array}{l}6.09 \\
2.33\end{array}$ & $\begin{array}{l}7.24 \\
2.82\end{array}$ & $\begin{array}{l}7.35 \\
2.99\end{array}$ & $\begin{array}{l}5.43 \\
2.13\end{array}$ \\
\hline
\end{tabular}


Appendix 1 Continued

\begin{tabular}{|c|c|c|c|c|c|c|}
\hline & \multirow[b]{2}{*}{ Exposure } & \multirow[b]{2}{*}{ Stimulus } & \multicolumn{4}{|c|}{ Feedback Period } \\
\hline & & & SAF-pre & DAF-pre & DAF-post & SAF-post \\
\hline \multirow{2}{*}{ Subject 8} & & Prose & 67.30 & 95.30 & 91.80 & 61.60 \\
\hline & Constant & $\begin{array}{l}\text { Lists } \\
\text { Sentences } \\
\text { Prose }\end{array}$ & $\begin{array}{r}6.69 \\
2.40 \\
70.60\end{array}$ & $\begin{array}{r}7.30 \\
3.28 \\
102.87\end{array}$ & $\begin{array}{r}7.11 \\
3.21 \\
96.37\end{array}$ & $\begin{array}{r}5.20 \\
2.31 \\
68.43\end{array}$ \\
\hline \multirow{2}{*}{ Subject 9} & Incremental & $\begin{array}{l}\text { Lists } \\
\text { Sentences } \\
\text { Prose }\end{array}$ & $\begin{array}{l}5.53 \\
2.10 \\
6.03\end{array}$ & $\begin{array}{r}6.50 \\
3.09 \\
81.37\end{array}$ & $\begin{array}{r}6.28 \\
2.76 \\
72.57\end{array}$ & $\begin{array}{r}4.20 \\
1.90 \\
56.10\end{array}$ \\
\hline & Constant & $\begin{array}{l}\text { Lists } \\
\text { Sentences } \\
\text { Prose }\end{array}$ & $\begin{array}{r}5.85 \\
2.24 \\
68.47\end{array}$ & $\begin{array}{r}10.58 \\
4.71 \\
117.47\end{array}$ & $\begin{array}{r}7.46 \\
3.13 \\
81.70\end{array}$ & $\begin{array}{r}4.71 \\
1.98 \\
61.13\end{array}$ \\
\hline \multirow{2}{*}{ Subject 10} & Incremental & $\begin{array}{l}\text { Lists } \\
\text { Sentences } \\
\text { Prose }\end{array}$ & $\begin{array}{r}3.95 \\
1.88 \\
57.63\end{array}$ & $\begin{array}{r}4.66 \\
1.99 \\
56.10\end{array}$ & $\begin{array}{r}3.99 \\
2.75 \\
58.23\end{array}$ & $\begin{array}{r}3.08 \\
1.63 \\
47.93\end{array}$ \\
\hline & Constant & $\begin{array}{l}\text { Lists } \\
\text { Sentences } \\
\text { Prose }\end{array}$ & $\begin{array}{r}5.73 \\
1.90 \\
58.27\end{array}$ & $\begin{array}{r}6.46 \\
2.11 \\
65.90\end{array}$ & $\begin{array}{r}5.66 \\
1.99 \\
66.77\end{array}$ & $\begin{array}{r}3.56 \\
1.60 \\
53.13\end{array}$ \\
\hline
\end{tabular}

Note-Subjects $1-5$ received the incremental condition in Session 1 and Subjects $6-10$ received the incremental condition in Session 2.

Appendix 2

Total Articulatory Errors on Lists, Sentences, and Prose Passages in Each Feedback Period During Incremental and Constant Delay Exposure Conditions

\begin{tabular}{|c|c|c|c|c|c|c|}
\hline & \multirow[b]{2}{*}{ Exposure } & \multirow[b]{2}{*}{ Stimulus } & \multicolumn{4}{|c|}{ Feedback Period } \\
\hline & & & SAF-pre & DAF-pre & DAF-post & SAF-post \\
\hline \multirow{6}{*}{ Subject 1} & \multirow{3}{*}{ Incremental } & Lists & 0 & 44 & 14 & 0 \\
\hline & & Sentences & 0 & 12 & 9 & 0 \\
\hline & & Prose & 1 & 43 & 37 & 0 \\
\hline & \multirow{3}{*}{ Constant } & Lists & 1 & 11 & 7 & 0 \\
\hline & & Sentences & 0 & 5 & 6 & 1 \\
\hline & & Prose & 1 & 26 & 12 & 1 \\
\hline \multirow{6}{*}{ Subject 2} & \multirow{3}{*}{ Incremental } & Lists & 0 & 7 & 4 & 0 \\
\hline & & Sentences & 0 & 2 & 5 & 1 \\
\hline & & Prose & 2 & 11 & 11 & 2 \\
\hline & \multirow{3}{*}{ Constant } & Lists & 0 & 0 & 0 & 0 \\
\hline & & Sentences & 1 & 3 & 5 & 0 \\
\hline & & Prose & 0 & 8 & 6 & 1 \\
\hline \multirow{6}{*}{ Subject 3} & \multirow{3}{*}{ Incremental } & Lists & 0 & 3 & 2 & 1 \\
\hline & & Sentences & 0 & 6 & 0 & 1 \\
\hline & & Prose & 1 & 14 & 10 & 0 \\
\hline & \multirow{3}{*}{ Constant } & Lists & 0 & 2 & 3 & 0 \\
\hline & & Sentences & 0 & 1 & 1 & 1 \\
\hline & & Prose & 1 & 12 & 7 & 1 \\
\hline \multirow{6}{*}{ Subject 4} & \multirow{3}{*}{ Incremental } & Lists & 2 & 8 & 6 & 0 \\
\hline & & Sentences & 0 & 8 & 3 & 0 \\
\hline & & Prose & 3 & 23 & 25 & 3 \\
\hline & \multirow{3}{*}{ Constant } & Lists & 0 & 6 & 7 & 0 \\
\hline & & Sentences & 1 & 4 & 7 & 2 \\
\hline & & Prose & 2 & 15 & 16 & 1 \\
\hline \multirow{8}{*}{ Subject 5} & \multirow{3}{*}{ Incremental } & Lists & 3 & 14 & 4 & 1 \\
\hline & & Sentences & 0 & 18 & 6 & 0 \\
\hline & & Prose & 1 & 36 & 16 & 5 \\
\hline & \multirow{3}{*}{ Constant } & Lists & 0 & 6 & 9 & 1 \\
\hline & & Sentences & 0 & 9 & 2 & 1 \\
\hline & & Prose & 1 & 29 & 22 & 0 \\
\hline & & Lists & 0 & 5 & 3 & 0 \\
\hline & Incremental & Sentences & 0 & 3 & 4 & 0 \\
\hline
\end{tabular}


Appendix 2 Continued

\begin{tabular}{|c|c|c|c|c|c|c|}
\hline & \multirow[b]{2}{*}{ Exposure } & \multirow[b]{2}{*}{ Stimulus } & \multicolumn{4}{|c|}{ Feedback Period } \\
\hline & & & SAF-pre & DAF-pre & DAF-post & SAF-post \\
\hline \multirow{4}{*}{ Subject 6} & & Prose & 0 & 24 & 14 & 1 \\
\hline & & Lists & 0 & 5 & 3 & 0 \\
\hline & Constant & Sentences & 1 & 7 & 5 & 2 \\
\hline & & Prose & 1 & 28 & 13 & 2 \\
\hline \multirow{6}{*}{ Subject 7} & & Lists & 0 & 2 & 0 & 0 \\
\hline & Incremental & Sentences & 1 & 0 & 0 & 0 \\
\hline & & Prose & 1 & 8 & 7 & 1 \\
\hline & & Lists & 0 & 7 & 1 & 1 \\
\hline & Constant & Sentences & 0 & 2 & 0 & 0 \\
\hline & & Prose & 3 & 6 & 6 & 1 \\
\hline \multirow{6}{*}{ Subject 8} & & Lists & 0 & 2 & 2 & 0 \\
\hline & Incremental & Sentences & 0 & 6 & 2 & 0 \\
\hline & & Prose & 4 & 17 & 5 & 1 \\
\hline & & Lists & 0 & 1 & 2 & 0 \\
\hline & Constant & Sentences & 0 & 9 & 1 & 0 \\
\hline & & Prose & 2 & 24 & 13 & 1 \\
\hline \multirow{6}{*}{ Subject 9} & & Lists & 0 & 0 & 0 & 0 \\
\hline & Incremental & Sentences & 0 & 4 & 0 & 0 \\
\hline & & Prose & 0 & 3 & 11 & 5 \\
\hline & & Lists & 2 & 1 & 0 & 2 \\
\hline & Constant & Sentences & 0 & 1 & 0 & 0 \\
\hline & & Prose & 3 & 4 & 7 & 1 \\
\hline \multirow{6}{*}{ Subject 10} & & Lists & 1 & 7 & 1 & 0 \\
\hline & Incremental & Sentences & 0 & 8 & 1 & 0 \\
\hline & & Prose & 2 & 23 & 10 & 2 \\
\hline & & Lists & 0 & 12 & 11 & 0 \\
\hline & Constant & Sentences & 0 & 3 & 3 & 0 \\
\hline & & Prose & 1 & 28 & 18 & 1 \\
\hline
\end{tabular}

\section{REFERENCE NOTE}

1. Rawnsley, A. I., \& Harris, J. D. Comparative analysis of normal speech and speech with delayed sidetone by means of sound spectrograms. USN Medical Research Laboratory, Report No. 248. 1954.

\section{REFERENCES}

Atkinson. C. J. Adaptation to delayed sidetone. Journal of Speech and Hearing Disorders, 1953, 18, 386-391.

BLACK, J. W. The effect of delayed sidetone on vocal rate and intensity. Joumal of Speech and Hearing Disorders, 1951. 16. 56-60.

BLack. J. W. The persistence of the effects of delayed sidetone. Journal of Speech and Hearing Disorders, 1955, 20, 65-68.

Chase, R. A., Harvey, S., Standfast, S., Rapin, I., \& Sutton, S. Comparison of the effects of delayed auditory feedback on speech and key tapping. Science, 1959, 129, 903-904.

EBEnholtz. S. M. Adaptation to a rotated visual field as a function of degree of tilt and exposure time. Journal of Experimental Psychology, 1966, 72. 629-634.

Ebenholtz. S. M. Optimal input rates for tilt adaptation. American Journal of Psychology, 1973, 86, 193-200.

Fairbanks, G. Selective vocal effects of delayed auditory feedback. Journal of Speech and Hearing Disorders. 1955, 20. 333-345.

Fairbanks, G., \& Guttman, N. Effects of delayed auditory feedback upon articulation. Journal of Speech and Hearing Research, 1958, 1. 12-22.

Fillenbaum. S. Adaptation with constant and variable delay in auditory feedback. Psychonomic Science. 1965, 3, 45-46.

Graybiel, A. Structural elements in the concept of motion sickness. A erospace Medicine. 1969, 40. 351-367.
Graybiel, A.. \& Wood, C. D. Rapid vestibular adaptation in a rotating environment by means of controlled head movements. Aerospace Medicine, 1969, 40, 638-643.

Hanley, C. N., \& TiffanY, W. R. An investigation into the use of electromechanically delayed sidetone in auditory testing. Journal of Speech and Hearing Disorders, 1954, 19, 367-374.

Hanley, C. N., TiffanY, W. R., \& Brungard, J. M. Skin resistance changes accompanying the sidetone test for auditory malingering. Joumal of Speech and Hearing Research, 1958, 1. 286-293.

Harris, C. Perceptual adaptation to inverted, reversed, and displaced vision. Psychological Review, 1965, 72, 419-444.

HeLd. R. Plasticity in sensory-motor systems. Scientific American, 1965. 213. 84-94.

Held. R.. \& Freedman, S. J. Plasticity in human sensorimotor control. Science, 1963, 142, 455-462.

Helmholtz, H. von. Handbuch der physiologischen Optik. Leipzig: Voss, 1866. [English translation: A treatise on physiological optics (Vol. 3. 3rd ed.) J. P. O. Southall (Ed.). New York: Dover. 1963.]

Howard. I. P. Displacing the optical array. In S. J. Freedman (Ed.). The neuropsychology of spatially oriented behavior. Homewood. Ill: Dorsey Press, 1968. Pp. 19-36.

HowARD. I. P..\& TEMPLeton, W. B. Visually-ind uced eye torsion and tilt adaptation. Vision Research, 1966, 4, 433-437.

KOHLER, I. Experiments with goggles. Scientific American, 1962, 206, 62-86.

LACKNER, J. R. Visual rearrangement affects auditory localization. Neuropsychologia. 1973, 11, 29-32. (a)

LACKNER. J. R. Role of posture in adaptation to visual rearrangement. Neuropsychologia, 1973, 11, 33-44. (b)

LACKNER, J. R. Influence of abnormal postural and sensory conditions on human sensorimotor localization. Environmental Biology and Medicinc. 1976. 2.139-177. (a) 
LACKNER, J. R. Some mechanisms underlying sensory and postural stability in man. Handbook of Sensory Physiology, 1976, in press. (b)

LACKNER, J. R., \& LEVINE, K. B. Speech production: Evidence for syntactically and phonologically determined units. Perception \& Psychophysics, 1975, 17, 107-113.

LACKNER, J. R., \& LoBovits, D. Adaptation to displaced vision: Evidence for prolonged aftereffects. Quarterly Journal of Experimental Psychology. 1977, 29, 65-69.

LEE. B. S. Effects of delayed speech feedback. Journal of the Acoustical Society of America, 1950, 22, 824-826. (a)

LEE. B. S. Some effects of sidetone delay. Journal of the Acoustical Society of America, 1950, 22, 639-640. (b)

LEE. B. S. Artificial stutter. Joumal of Speech and Hearing Disorders, 1951, 16, 53-55.

Leith, W. R., \& Pronko, N. H. Speech under stress: A study of its disintegration. Speech Monographs, 1957, 24, 285-291.

Rock, I. The nature of perceptual adaptation. New York: Basic Books, 1966.

Shattuck, S. R., \& Lackner, J. R. Speech production: Contribution of syntactic structure. Perceptual and Motor Skills, 1975, 40. $931-936$

Sмiтн. K. U. Delayed sensory feedback and behavior. Philadelphia: Saunders. 1962.

SNyder, F. W., \& Pronko, N. H. Vision with spatial inversion. Wichita. Kansas: McCormick-Armstrong. 1952.

SPILKA, B. Some vocal effects of different reading passages and time delays in speech feedback. Journal of Speech and Hearing Disorders. 1954. 19. 37-47.

Stratton. G. M. Upright vision and the retinal image. Psychological Review, 1897, 4, 182-187.

Tiffany, W. R., \& Hanley, C. N. Adaptation to delayed sidetone. Journal of Speech and Hearing Disorders. 1956. 21, 164-172.

Timmons. B. A. Sex as a factor influencing sensitivity to delayed auditory feedback. Perceptual and Motor Skills, 1971, 32. 824-826.

Winchester. R. A., Gibbons, E. W., \& Krebs, D. F. Adaptation to sustained delayed sidetone. Journal of Speech and Hearing Disorders. 1959. 24. 25-28.

Wooster. M. Certain factors in the development of a new spatial coordination. Psychology Monographs, 1923, (4, Whole No. 146).

YACHZEL, B. R., \& LACKNER, J. R. Adaptation to displaced vision: Evidence for transfer of adaptation and long-lasting aftereffects. Perception \& Psychophysics, 1977, 22. 147-151.

Zalosh, S., \& Saltzman, L. F. Aftereffects of delayed auditory feedback. Perceptual and Motor Skills, 1965, 20, 817-823.

(Received for publication February 7, 1977; revision accepted July 4, 1977.) 